\title{
The first impact factor for the Polish Archives of Internal Medicine - June 2012
}

\author{
Anetta Undas \\ Editor-in-chief, Polish Archives of Internal Medicine
}

Correspondence to:

Prof. Anetta Undas, MD, PhD, Instytut Kardiologii, Uniwersytet Jagielloński, Collegium Medicum, ul. Prądnicka 80 31-202 Kraków, Poland, phone: + 4812-614-30-04 fax: +4812-423-39-00, e-mail:mmundas@cyfkr.edu.pl Received: July 7. 2012. Accepted: July 7, 2012 Conflict of interest: none declared. Pol Arch Med Wewn. 2012; 122 (7-8): $317-319$ Copyright by Medycyna Praktyczna, Kraków 2012
A widely applied measure of the quality of biomedical journal is the so called journal impact factor, an index devised by Eugene Garfield to quantify the extent to which the articles of that journal are cited in other peer-reviewed publications. The impact factor is computed as the quotient $\mathrm{A} / \mathrm{B}$, where $\mathrm{A}$ is the total number of times that articles published in a journal in 2 consecutive years (e.g., 2009 and 2010) were cited in other articles during the following year (e.g., 2011), and B is the total number of "citable items" published by that journal in those 2 years. The impact factor is issued each year at the end of June by Thomson Reuters in Philadelphia and reflects the frequency of citations of the papers published in a given journal. An obvious shortcoming of the impact factor, so-computed, is that it represents merely a numeric average that does not shed light on the extent to which the individual articles of a journal contribute to its overall citation impact. However, this approach to measure the quality of scientific journals gives credit to previous publications, to some extent acknowledges the integrity of their authors and the relevance of their observations. Papers that are cited have by definition stimulated and influenced the work of others. On the other hand, in most journals, including the most reputable titles, up to a third of all publications are not cited even once in the next year.

The Polish Archives of Internal Medicine (Pol Arch Med Wewn), established in 1923, covers all areas of internal medicine, including basic science when it is highly relevant to clinical medicine.

The journal received its first impact factor of 1.367 in June 2012. Our estimation from the end of 2011, which predicted our impact factor to be approximately 1.3, turned out to be quite precise. In the years 2009 and 2010, there were 188 "citable items", including reviews, original articles, and case reports (published only in 2009); editorials are always excluded. Our articles were cited 257 times from January to December 2011.
The first impact factor greater than 1 is an enor mous success of all internists in Poland (TABle). I perceive it in this manner because the Pol Arch Med Wewn is the official journal of the Polish Society of Internal Medicine. The current President of our Society, Professor Tomasz Guzik, served as a dedicated Vice-Editor of the Pol Arch Med Wewn from January 2010 till April 2012 when he was appointed to lead our community for the next 4 years, and this is additional evidence for the im portance of the journal in Poland. Such a high impact factor is a true recognition for our journal and the Society. We owe a huge debt of gratitude to previous editors, Professors Artur Czyżyk, Tadeusz Orłowski, Andrzej Biernacki, Witold E. Orłowski, Władysław Janowski, and Władysław A. Gluziński, for their efforts which now allow us, the present team, to witness the true success of receiving the first impact factor.

Without substantial contribution of our au thors and supporters, we would not have been able to make it. I greatly appreciate those who shared with us their novel, interesting, and relevant findings, which attracted particular attention of peers in 2011 and were most cited in 2011 (4 times or more). Among original research papers, the essence of scientific journals, the most cited articles dealt with surprisingly diverse issues mostly related to therapy of chronic diseases.

My team has reported potentially beneficial simvastatin-induced alterations in plasma fibrin clot characteristics, including increased clot permeability and shortened lysis time, in apparently healthy subjects with low-density lipoprotein cholesterol $<3.4 \mathrm{mmol} / \mathrm{l}$ and varying serum C-reactive protein (CRP) concentrations. ${ }^{1}$ This novel antithrombotic mechanism of statins' action detectable in vivo was associated with anti-inflammatory effects, as evidenced by correlations of fibrin clot variables with CRP levels, which dropped significantly as expected based on previous small and large clinical studies. This report increased our knowledge on an intriguing 
TABLE Impact factors of Polish biomedical journals (2011 Journal Citation Reports ${ }^{\circledR}$ )

\begin{tabular}{|c|c|c|c|}
\hline & Abbreviated journal title & ISSN & Impact factor \\
\hline 1 & Pharmacol Rep & $1734-1140$ & 2.445 \\
\hline 2 & Ann Agr Env Med & $1232-1966$ & 2.311 \\
\hline 3 & J Physiol Pharmacol & $0867-5910$ & 2.267 \\
\hline 4 & Acta Neurobiol Exp & $0065-1400$ & 2.110 \\
\hline 5 & Ann Transpl & $1425-9524$ & 2.020 \\
\hline 6 & Reprod Biol & $1642-431 X$ & 1.921 \\
\hline 7 & Hered Cancer Clin Pr & $1731-2302$ & 1.680 \\
\hline 8 & J Appl Genet & $1234-1983$ & 1.664 \\
\hline 9 & Pol Arch Med Wewn & 0032-3772 & 1.367 \\
\hline 10 & Cardiol J & $1897-5593$ & 1.309 \\
\hline 11 & Endokrynol Pol & $0423-104 X$ & 1.239 \\
\hline 12 & Folia Neuropathol & $1641-4640$ & 1.234 \\
\hline 13 & Int J Occup Med Env & $1232-1087$ & 1.227 \\
\hline 14 & Arch Med Sci & $1734-1922$ & 1.214 \\
\hline 15 & Cent Eur J Biol & $1895-104 X$ & 1.000 \\
\hline 16 & Videosurgery Miniinv & $1895-4588$ & 1.000 \\
\hline 17 & Adv Med Sci-Poland & $1896-1126$ & 0.952 \\
\hline 18 & Acta Pol Pharm & $0001-6837$ & 0.663 \\
\hline 19 & Postep Hig Med Dosw & $0032-5449$ & 0.654 \\
\hline 20 & Folia Morphol & $0015-5659$ & 0.521 \\
\hline 21 & Kardiol Pol & $0022-9032$ & 0.515 \\
\hline 22 & Neurol Neurochir Pol & $0028-3843$ & 0.433 \\
\hline 23 & Ginekol Pol & $0017-0011$ & 0.411 \\
\hline 24 & Postep Derm Alergol & 1642-395X & 0.357 \\
\hline 25 & Pol J Pathol & $1233-9687$ & 0.347 \\
\hline 26 & Cent Eur J Immunol & $1426-3912$ & 0.317 \\
\hline 27 & Cent Eur J Med & $1895-1058$ & 0.312 \\
\hline 28 & Med Pr & $0465-5893$ & 0.303 \\
\hline 29 & Postep Kardiol Inter & $1734-9338$ & 0.215 \\
\hline 30 & Psychiatr Pol & $0033-2674$ & 0.195 \\
\hline 31 & Prz Menopauzalny & $1643-8876$ & 0.190 \\
\hline 32 & Adv Clin Exp Med & $1899-5276$ & 0.176 \\
\hline 33 & Postep Mikrobiol & $0079-4252$ & 0.151 \\
\hline 34 & Kardiochir Torakochir Pol & $1731-5530$ & 0.135 \\
\hline 35 & Wspolczesna Onkol & $1428-2526$ & 0.107 \\
\hline 36 & Postepy Biol Komorki & $0324-833 x$ & 0.073 \\
\hline 37 & Prz Gastroenterol & $1895-5770$ & 0.067 \\
\hline
\end{tabular}

reduction in the risk of thrombosis observed in subjects receiving various statins.

Tomczak-Watras et al. ${ }^{2}$ showed the effects of a 6-month anemia therapy with recombinant human erythropoietin on glomerular filtration rate (GFR) and renal blood flow in relation to hemoglobin, alterations in heart function, and total peripheral resistance in patients with chronic kidney disease (CKD) treated conservatively. This small though interesting study demonstrated that renal anemia correction is associated with a decrease in left ventricular end-diastolic dimension index, left ventricular end-diastolic volume index, stroke volume index, and cardiac index, along with increased total peripheral vascular resistance index. Interestingly, such therapy in patients with stage 3 and 4 CKD with desirable blood pressure control had no effect on renal function despite changes in the left ventricular function and peripheral resistance.

Skoczyńska et al. ${ }^{3}$ reminded our readers that postprandial lipemia in diabetes and its modulation is a complex issue. Their report showed that in diabetic patients and those with hyperlipemia and free of diabetes compared with normolipemic subjects, treatment with simvastatin or fenofibrate decreased fasting lipid, CRP, and postprandial lipemia. It was concluded that lipid intolerance detected in a postprandial lipemia test might help identify patients that can benefit from hypolipemic therapy.

Statins have also drawn the attention of readers to the paper by Kaczmarek et al. ${ }^{4}$ Given the increasing prevalence of chronic obstructive pulmonary disease (COPD) worldwide and the data indicating that statins known to produce anti-inflammatory properties may reduce mortality also in COPD patients, the effects of simvastatin $40 \mathrm{mg} /$ day for 3 months on inflammatory markers were worth investigating. After 2 weeks as well as 3 months of simvastatin treatment, no changes in circulating inflammatory markers were observed despite improved lipid profile. This study provided additional evidence that statins are not potent enough to suppress enhanced inflammatory state reflected by markedly elevated CRP.

The most cited review articles from 2009 or 2010 are presented below.

A review on the treatment of major depressive disorders resulting in a high risk of suicide worldwide has been highly cited. Koenig et al. ${ }^{5}$ reviewed the practical aspects of the use of antidepressants that represent the first-line therapy for those disorders, namely selective serotonin reuptake inhibitors, serotonin and norepinephrine reuptake inhibitors, and the norepinephrine-dopamine reuptake inhibitor. Comments on the assessment of medication response and management of potential side effects have been of particular value in this excellent paper.

Chow et al. ${ }^{6}$ have addressed the vital question of how to use opioids on a long-term basis in patients with chronic noncancer pain in everyday practice. This review article was based on the key practical recommendations from a systematic review on this issue prepared by the expert panel for the American Pain Society and the American Academy of Pain Medicine. Chow addressed patient selection and risk stratification, informed consent and opioid management plans, initiation and titration of chronic opioid therapy, use of methadone, monitoring of patients, use of opioids in high-risk patients, assessment of aberrant drug-related behaviors, dose escalations and high-dose opioid therapy, opioid rotation, indications for discontinuation of therapy, prevention and management of opioid-related adverse effects, driving, and work safety. ${ }^{6}$

The most cited paper from the field of gastroenterology was the review published by Owczarek 
et al. ${ }^{7}$ The authors reviewed the available data on the rationale for biological therapy of ulcerative colitis, Crohn's disease, and indeterminate colitis, i.e., inflammatory bowel diseases (IBD). Complex cellular and humoral immune mechanisms underlying the progression of IBD with the key role of tumor necrosis factor- $\alpha$ provided the pathophysiological background for implementing a biological strategy based on infliximab and adalimumab, currently used in Poland. Neutralization of proinflammatory cytokines, use of anti-inflammatory cytokines, and inhibition of neutrophil adhesion led to clinical benefits from such therapy, including longer duration of remission and improved quality of life. Not surprisingly, this comprehensive review published in January 2009 in the Pol Arch Med Wewn was frequently downloaded, read, and cited by investigators.

Finally, in the era of new oral anticoagulants, namely selective inhibitors of factor $\mathrm{Xa}$ and thrombin, the review by Karthikeyan et al. ${ }^{8}$ could not have gone unnoticed and uncited. The elimination of the need for routine laboratory monitoring and good safety profile made dabigatran an extremely attractive therapeutic option that is increasingly appreciated in most countries. Of note, the review expertly addressed the issue of the feasibility of replacing warfarin with dabigatran for different indications. Since new anticoagulants have the potential to improve the quality of anticoagulation worldwide, we keep publishing expert review articles presenting recommendations and suggestions in this rapidly evolving field of vital practical implications.

As Editor-in-Chief of the Pol Arch Med Wewn since 2008, my goal is to steadily improve the quality of the articles published in the journal. Our acceptance rate is now less than $50 \%$. I trust that the impact factor in 2012 will be higher than the first one. Given the fact that within the first 5 months of this year, there are papers from the years 2010 and 2011 cited 4 times, both original, e.g., the study by Szułdrzynski et al. ${ }^{9}$ on oxidative stress in acute myocardial infarction, and reviews, e.g., that by Holecki and Więcek ${ }^{10}$ on the relationship between body fat mass and bone metabolism, a higher 2012 impact factor is a realistic expectation.

Together with a new Vice-Editor, Grzegorz Gajos, MD, PhD, we try our best to follow the principles of good publishing practice and proper scientific conduct in order to publish interesting and methodologically sound papers. We have decided to give a chance for interdisciplinary papers that could be relevant not only for internal medicine doctors, but also surgeons or other specialties, and we will judge their impact in the subsequent years. We will also publish state-of-the-art reviews but only if written by authors who contributed to the field as evidenced by a few papers in peer-reviewed journals and, therefore, we intend to focus predominantly on invited reviews. In almost all cases, a negative review is an ominous sign for all submitted papers in our journal even if the other is enthusiastic. We are committed to providing fair and balanced reviews in a timely manner to ensure quick publication of the accepted articles, first online, then in print, within 3 months since acceptance. We are plannning to further improve the web-based editorial process. With continued support of our hard-working expert reviewers, we keep striving for complete elimination of plagiarism and autoplagiarism, which is much tougher than I ever thought before having entered my current editorial position. What is most important, we need support of all our readers and, in particular, Polish scientists in citing the work published by our journal and in submitting interesting papers. We look forward to working with all our friends and supporters to further enhance the standing of the journal.

I have decided to dedicate the first impact factor to the late Professor Andrzej Szczeklik. Last year, I had a feeling that he was the only one who truly and sincerely believed that this journal would make it. And we have made it, as I promised to him, the Board of the Polish Society of Internal Medicine, and all authors of the published papers 2 years ago.

To sum up, I welcome input from all contributors to the Pol Arch Med Wewn on how we can best serve internal medicine and related science in Poland and abroad. In the coming months, assessment of all aspects of the journal will be performed to implement improvements. I hope that we all, readers, authors, and reviewers, are excited to continue to assist in the ascent of our journal in this highly competitive world of biomedical science.

\section{REFERENCES}

1 Undas A, Topór-Madry R, Tracz W. Simvastatin increases clot perme ability and susceptibility to lysis in patients with LDL cholesterol below 3.4 mmol/l. Pol Arch Med Wewn. 2009; 119: 354-359.

2 Tomczak-Watras W, Strózecki P, Zuchora Z, et al. Influence of the 6-month anemia therapy with erythropoietin on renal function and some hemodynamic parameters in predialysis patients. Pol Arch Med Wewn. 2009; 119: 45-51.

3 Skoczyńska A, Kreczyńska B, Poręba R. Postprandial lipemia in diabetic men during hypolipemic therapy. Pol Arch Med Wewn. 2009; 119: 461-468.

4 Kaczmarek P, Stadek K, Skucha W, et al. The influence of simvastatin on selected inflammatory markers in patients with chronic obstructive pulmonary disease. Pol Arch Med Wewn. 2010; 120: 11-17.

5 Koenig AM, Thase ME. First-line pharmacotherapies for depression what is the best choice? Pol Arch Med Wewn. 2009; 119: 478-486.

6 Chou R. 2009 Clinical Guidelines from the American Pain Society and the American Academy of Pain Medicine on the use of chronic opioid therapy in chronic noncancer pain: what are the key messages for clinical practice? Pol Arch Med Wewn. 2009; 119: 469-477.

7 Owczarek D, Cibor D, Szczepanek M, Mach T. Biological therapy of inflammatory bowel disease. Pol Arch Med Wewn. 2009; 119: 84-88.

8 Karthikeyan G, Eikelboom JW, Hirsh J. New oral anticoagulants: not quite there yet. Pol Arch Med Wewn. 2009; 119: 53-58.

9 Szułdrzyński K, Zalewski J, Machnik A, Zmudka K. Elevated levels of 8-iso-prostaglandin F2alpha in acute coronary syndromes are associated with systemic and local platelet activation. Pol Arch Med Wewn. 2010; 120: $19-24$

10 Holecki M, Więcek $A$. Relationship between body fat mass and bone metabolism. Pol Arch Med Wewn. 2010; 120: 361-367. 